ISSN 0258-7122 (Print), 2408-8293 (Online)

Bangladesh J. Agril. Res. 41(4): 647-656, December 2016

\title{
GENETIC DIVERGENCE ANALYSIS IN PAPAYA (Carica papaya L.) GENOTYPES
}

\author{
N. ARA ${ }^{1}$, M. MONIRUZZAMAN ${ }^{2}$, FERDOUSI BEGUM ${ }^{3}$ \\ M. MONIRUZZAMAN ${ }^{4}$ AND R. KHATOON ${ }^{5}$
}

\begin{abstract}
The experiment on papaya (Carica papaya L.) consisting of fourteen genotypes from diversd gene pool was conducted at the Regional Agricultural Research Station, Ishurdi, Pabna during April 2013 to May 2014 to study the nature and magnitude of genetic divergence and eventually identification of suitable genotypes for use in breeding program. Multivariate analysis was subjected to assess the genetic diversity and Mahalanobis' generalized distance $\left(\mathrm{D}^{2}\right)$ was used to assess the divergence present among the genotypes. The fourteen genotypes were grouped into four clusters. The cluster IV had the maximum genotypes (5) followed by cluster I having 4 genotypes and cluster II having 3 genotypes. Cluster III had the minimum genotypes (2). The inter-cluster distances were greater than intra-cluster distances in all cases, suggesting wider genetic diversity among the genotypes of different groups. The highest intracluster distance was observed in cluster III and the lowest in cluster II. The maximum inter-cluster distance was estimated between clusters I and IV (11.3212), moderate distance between clusters II and IV (9.961) and clusters III and IV (7.568), and that of the lowest between clusters I and III. Cluster III recorded the highest mean values for fruit length, plant height at last harvest, number of fruits/plant, weight of fruits/plant and fruit yield, while cluster IV exhibited the maximum mean values for pulp thickness, plant height at 1 st harvest and the second highest mean values for fruit length, fruit breadth and TSS. Therefore, more emphasis should be given on cluster III for selecting genotypes as parents for crossing with the genotypes of cluster IV which may produce new recombinants with desired traits.
\end{abstract}

Keywords: Genetic diversity, Papaya (Carica papaya L.), Mahalanobis' distance $\left(\mathrm{D}^{2}\right)$ and Cluster analysis

\section{Introduction}

Papaya (Carica papaya L) is one of the most important fruits cultivated throughout the tropical and subtropical regions of the world. It is a native of tropical America and was introduced from the Philippines through Malaysia into India during $16^{\text {th }}$ century (Saran et al., 2015). It is grown throughout Bangladesh particularly as homestead and widely cultivated in Rajshahi, Bogra, Pabna, Chittagong Hill Districts, Rangpur, Jesssore, Ishurdi, Mymensingh and Dhaka

${ }^{1 \& 2}$ Principal Scientific Officer, HRC, Bangladesh Agricultural Research Institute (BARI), ${ }^{3}$ Scientific Officer, Plant Breeding Division, BARI, ${ }^{4}{ }^{5}$ Scientific Officer, HRC, BARI, Gazipur, Bangladesh. 
(Ahmed, 1984; Anon., 2014). Papaya is eaten both as fresh and cooked. Ripe papaya fruit is wonderful for their colour, flavor and taste. Nutritionally, the papaya is a good source of calcium and an excellent source of vita A and vita C (Nakasone and Paull, 1998). It has also medicinal values (Bose, 1990).

Although papaya is one of the most important fruits, very less importance has been given for its improvement. Till today in Bangladesh there are two released varieties of papaya available for cultivation by the enthusiastic farmers. These two varieties are BARI Papaya-1 and BU-Papaya -1. BARI Papaya-1 (Shahi papaya) is an excellent variety, but its fruit quality has been degenerated due to lack of maintenance breeding. Therefore, it has become utmost necessary to develop more suitable varieties to fulfill the present ever increasing demand of this fruit for cultivation. For this purpose fruit scientists of Regional Agricultural Research Station, Ishurdi, Pabna under BARI collected some papaya genotypes from Ishurdi, Jessore, Bogra, Pabna, and Rajshahi districts in April 2013.

A sound germplasm collection with distinct variability for the desirable characters is the basic requirement of any crop improvement program (Singahania et al., 2006). In addition, crop improvement is primarily based on extensive evaluation of germplasm (Ghafoor et al., 2001). Information about the relationship among desired breeding populations and the genetic diversity in available germplasm is important for designing effective breeding programme. This helps choose desirable parents for establishing new breeding population. Better knowledge on genetic diversity or genetic similarity could help sustain long term selection gain and it is an established fact genetic divergence is a useful tool for an efficient choice of parents for hybridization to develop high yield potential cultivars (Chowdhury et al., 2002). The utility of multivariate analysis and the use of generalized distance $\left(\mathrm{D}^{2}\right)$ as a quantitative measure of genetic divergence are well illustrated (Bhatt, 1973). Crosses between genetically diverse parents would manifest more heterosis than crosses of between closely related parents (Singh, 1991; Shukla and Singh, 2002). Papaya germplasm shows considerable phenotypic variation for many horticultural traits (Ocampa et al., 2006). As papaya is an important fruit, it needs a great deal of critical evaluation of the available types for selection of the improved types with high yield potential. Very few studies have been made regarding evaluation of papaya germplasm pertaining to its morphological attributes and yield performance. So information on the local papaya genotypes on the basis of diversity is inadequate in Bangladesh. Selection of better plant type can be of immense value to the breeder for further improvement and development of the crop. Therefore, the present investigation was undertaken to study the nature and magnitude of genetic divergence and identification of suitable genotypes for use in breeding program for broadening the genetic base in papaya. 


\section{Materials and Method}

The experiment was conducted at the Regional Agricultural Research Station, Ishurdi, Pabna during April 2013 to May 2014. Fourteen genotypes of papaya were included in this study, collected from different districts of Bangladesh. The places of seed collections are presented in the Table 1. The experiment was laid out in a randomized complete block (RCB) design having fourteen treatments (14 genotypes) with three replications. The land was ploughed well and $15 \mathrm{~cm}$ raised plots were prepared. The unit plot size and plant spacing were $8 \mathrm{~m} \times 2 \mathrm{~m}$ and $2 \mathrm{mx}$ $2 \mathrm{~m}$, respectively. The seeds of all genotypes were sown singly in poly ethylene bag $(7 \mathrm{~cm} \times 8 \mathrm{~cm})$ on 25 February, 2013. The polyethylene bag was filled with sandy loam soil and well decomposed cowdung in the ratio of $2: 1$. Pits of $50 \mathrm{~cm}$ x $50 \mathrm{~cm} \times 50 \mathrm{~cm}$ size were dug and exposed to sun for a week before filling up with the top soil. Three seedlings of fifty days old were planted in each pit and on 15 April, 2013. Each plant was fertilized $15 \mathrm{~kg}$ cowdung, 500g TSP, $250 \mathrm{~g}$ MoP, $280 \mathrm{~g}$ Gypsum, $25 \mathrm{~g}$ Boric acid and 20g Zinc sulphate. The entire amount of compost, TSP, Gypsum, Boric acid and Zinc sulphate were applied at the pit.

Table 1. Location and no. of collected papaya germplasm

\begin{tabular}{l|c|c|c}
\hline Serial no. & Acc. No. & $\begin{array}{c}\text { Location of } \\
\text { collection }\end{array}$ & $\begin{array}{c}\text { Total No. of collected } \\
\text { fruits }\end{array}$ \\
\hline 1 & ISD001 & Ishurdi & 3 \\
2 & ISD002 & Ishurdi & 2 \\
3 & ISD024 & Ishurdi & 2 \\
4 & PB018 & Bogura & 2 \\
5 & PP038 & Pabna & 2 \\
6 & PP031 & Pabna & 2 \\
7 & PB013 & Bogura & 3 \\
8 & PB029 & Bogura & 2 \\
9 & PR007 & Rajshahi & 2 \\
10 & PP036 & Pabna & 2 \\
11 & PJ022 & Jessore & 3 \\
12 & PB014 & Bogura & 1 \\
13 & PJ045 & Jessore & 2 \\
14 & ISD003 & Ishurdi & 2 \\
\hline
\end{tabular}

Acc. No. $=$ Accession number

Urea and MoP were applied @ 50g/plant and 25g/plant, respectively at 30 days interval. Each plant was provided with a strong bamboo stick to protect against 
heavy wind. The intercultural operations (weeding mulching, irrigation, insecticide spray etc.) were done as and when necessary. Male plants were cut off after emergence of flower keeping one female plant in each pit. Ten percent male plant was kept in the experimental field for better pollination. Data on fruit length $(\mathrm{cm})$, fruit breadth $(\mathrm{cm})$, cavity length $(\mathrm{cm})$, cavity breadth $(\mathrm{cm})$, total soluble solid $(\mathrm{TSS} \%)$, pulp thickness $(\mathrm{cm})$, number of seeds/fruit, weight of seeds/fruit $(\mathrm{g})$, skin weight/fruit $(\mathrm{g})$, plant height at $1^{\text {st }}$ harvest $(\mathrm{cm})$, plant height at last harvest $(\mathrm{cm})$, base girth at $1^{\text {st }}$ harvest $(\mathrm{cm})$, base girth at last harvest $(\mathrm{cm})$, number of fruits/ plant, weight of fruits /plant $(\mathrm{kg})$ and fruit yield $(\mathrm{t} / \mathrm{ha})$ were recorded. (\%). Data on these 20 quantitative characters were used for diversity analysis. Genetic diversity was studied following Mahalanobis' (1936) generalized distance $\left(\mathrm{D}^{2}\right)$ extended by Rao (1952). Based on $\mathrm{D}^{2}$ values, the genotypes were grouped into clusters following the method suggested by Tocher (Rao, 1952). Intra and inter -cluster distances were calculated by the methods of Singh and Chaudhury (1985). Statistical analyses were carried out using Genestat 5 software.

\section{Results and Discussion}

The analysis of variance showed significant differences among the 14 genotypes for all the 16 characters. Besides, descriptic statistics (range, SD and CV (\%) showed great variation in most of the characters (Table 2). Fruit length ranged from 15.33-21.93 cm being the highest in PB029 followed by PJ022 and the lowest in ISD024. The range 10.33-14.33 cm was noticed in respect of fruit breadth, where the highest was found in PJ022 and the lowest in ISD024. Sudha et al. (2013) evaluated 73 papaya genotypes and reported that the ranges of fruit length, and fruit breadth were $18-38 \mathrm{~cm}$ and $21-45.20 \mathrm{~cm}$, respectively. Length of fruit cavity ranged from $11.43-17.27 \mathrm{~cm}$, the maximum in PB029 followed by PJ022 and the minimum in PP031, but breadth of fruit cavity ranged from 6.57 $\mathrm{cm}$ (ISD003) - $10.27 \mathrm{~cm}$ (PP031). The percent TSS ranged from $6.40-13.90 \%$. The maximum TSS\% was recorded in PB018 followed by PP036 and the minimum, in ISD002. Pulp thickness of the fruit ranged from $2.40-3.17 \mathrm{~cm}$. Evaluating 24 papaya germplasm lines. Jambhale et al. (2014) reported that TSS ranged from $12.77 \%-13.91 \%$ and pulp thickness from $1.85 \mathrm{~cm}-2.74 \mathrm{~cm}$. According to Sudha et al. (2013) the ranges of TSS and pulp thickness were 6.50 - $13.60 \%$ and $1.50-3.40 \mathrm{~cm}$, respectively. Saran et al. (2015) reported that in case of TSS the range was 7.40-15.20\%, while in case of pulp thickness that was $2.50-3.70 \mathrm{~cm}$. Wide range of variation was observed among 14 papaya genotypes in number of seeds/fruit, which ranged from $174.50-786.33$. The genotype PB014 produced maximum number of seeds/fruit (786.33) followed by PB013 (PB013) and the genotype ISD001, the minimum (174.50). Wide variation was also observed among the genotypes in respect of weight of seeds/fruit that ranged from 27.50 g (ISD001)- 121.87 $\mathrm{g}$ (PJ022). Skin weight/fruit ranged from $115.87 \mathrm{~g}$ (PB018)- $230.83 \mathrm{~g}$ (PP036). Plant height at 1st 
harvest ranged from $110 \mathrm{~cm}$ (PJ022)- $200 \mathrm{~cm}$ (ISD001), but the range 152.50 $235.17 \mathrm{~cm}$ was observed in respect of plant height at last harvest, where the maximum was found in PB038 followed by ISD024 $(228.33 \mathrm{~cm})$ and the minimum in PJ022. Base girth at $1^{\text {st }}$ harvest and last harvest ranged from $19 \mathrm{~cm}$ (PJ022) to $27.67 \mathrm{~cm}$ (PB013) and $24.50 \mathrm{~cm}$ (PB014) to 36.33 (PJ045), respectively. Number of fruits/plant ranged from 14.36 to 39.34 , being the highest in PB038 PP036 (37/plant) and the lowest in PJ045. Marked variation was observed among the genotypes in respect of weight of fruits/plant that ranged from $10.30 \mathrm{~kg}$ (PJ045) - 50.20 kg (PB038). Anon. (2014) reported that average weight of fruits/tree was $22-25 \mathrm{~kg}$. Jambhale et al. (2014) reported that number of fruits/plant and weight of fruits/plant ranged from 15.88-29.88 and $15.56-30.75 \mathrm{~kg}$. Saran et al. (2015) got weight of fruits/plant in the range of 5.40$63.70 \mathrm{~kg}$. Genotypes of papaya under investigation showed a wide range of variability among themselves in respect of fruit yield/ha that ranged from 25.75 t/ha (PJ045) to $125.42 \mathrm{t} / \mathrm{ha}$ (PB038) followed by $103.92 \mathrm{t} / \mathrm{ha}$ (PR007) and 101.83 t/ha (PP036). The larger values of standard deviation (SD) for number of seeds/fruit, weight of seeds/fruit, skin weight/fruit, plant height at first harvest, plant height at last harvest, fruit yield/ha indicated that a wide range of variability exists among those characters. The characters TSS\%, number of seeds/fruit, weight of seeds/fruit, skin weight/fruit, plant height at $1^{\text {st }}$ harvest, number of fruits/plant, weight of fruits/plant and fruit yield/ha possessed higher percentage of coefficient of variation (CV\%) suggesting that there exists a wide variation among them. Thus, descriptic statistics revealed wide variation in most of the characters of fourteen papaya genotypes, indicating adequate genetic variability in the experimental material.

Table 2. Range, mean, standard deviation (SD) and Co-efficient of variation in different characters of fourteen papaya genotypes

\begin{tabular}{lccccc}
\hline \multicolumn{1}{c|}{ Character } & Range & Mean & SD & CV\% \\
\hline Fruit length $(\mathrm{cm})$ & $15.33-21.93$ & 17.72 & 1.74 & 9.83 \\
Fruit breadth (cm) & $10.33-14.33$ & 12.79 & 1.07 & 8.36 \\
Cavity length (cm) & $11.43-17.27$ & 13.68 & 1.63 & 11.91 \\
Cavity breadth (cm) & $6.57-10.27$ & 8.12 & 0.98 & 12.11 \\
TSS\% & $6.40-13.90$ & 9.28 & 2.13 & 22.95 \\
Pulp thickness (cm) & $2.40-3.17$ & 2.76 & 0.24 & 8.75 \\
No of seed & $174.7-768.33$ & 409.32 & 171.39 & 41.87 \\
Weight of seed (g) & $27.50-121.87$ & 67.47 & 30.53 & 45.26 \\
Skin weight (g) & $115.57-230.83$ & 162.71 & 32.38 & 19.90 \\
Plant height at 1st harvest (cm) & $110.0-200.0$ & 83.48 & 19.26 & 23.07 \\
Plant height at last harvest (cm) & $152.50-235$ & 202.80 & 23.54 & 11.61 \\
Base girth at 1st harvest (cm) & $19.00-27.67$ & 23.81 & 2.68 & 11.28 \\
Base girth at last harvest (cm) & $24.50-36.33$ & 30.50 & 3.79 & 12.43 \\
No of fruits/plant & $14.36-39.34$ & 28.56 & 6.88 & 24.09 \\
Weight of fruit/plant (kg) & $10.30-50.20$ & 33.49 & 9.52 & 28.44 \\
yield (t/ha) & $25.75-125.42$ & 83.68 & 23.78 & 28.41 \\
\hline
\end{tabular}


Table 3. Distribution of 14 papaya genotypes in different clusters

\begin{tabular}{c|c|l|l}
\hline Cluster no & No of genotypes & Genotypes & Accession No. \\
\hline I & 4 & $1,3,7,11$ & ISD001, ISD024, PB013, PJ022 \\
II & 3 & $2,4,5$ & ISD002, PB018,PP038 \\
III & 2 & 6,9 & PP031, PR007 \\
IV & 5 & $8,10,12,13,14$ & $\begin{array}{l}\text { PB029, PP036, PB014, PJ045, } \\
\text { ISD003 }\end{array}$ \\
\hline
\end{tabular}

Table 4. Intra (bold) and inter cluster distances among four clusters of 14 papaya genotypes

\begin{tabular}{c|c|c|c|c}
\hline Cluster & I & II & III & IV \\
\hline I & $\mathbf{1 . 0 3 3}$ & 4.87 & 3.755 & 11.312 \\
II & & $\mathbf{0 . 9 1 1}$ & 4.748 & 9.961 \\
III & & & $\mathbf{1 . 2 6 3}$ & 7.568 \\
IV & & & & $\mathbf{1 . 1 9 8}$ \\
\hline
\end{tabular}

All the 14 papaya genotypes under test were grouped into four clusters (Table 3). The large number of genotypes was included in cluster IV (5 genotypes), followed by cluster I ( 4 genotypes) and cluster II (3 genotypes). Cluster III consisted of only two genotypes. The clustering was also confirmed by Fig. 1. Sudha et al. (2013) obtained 4 clusters for 73 papaya genotypes. Saran et al. (2015) also got 4 clusters for 24 papaya genotypes using 29 characters.

The average intra-cluster $\mathrm{D}^{2}$ value was the highest (1.263) between in cluster III and the lowest (0.911) in cluster II (Table 4). The intra-cluster distances were low for all of 4 clusters which indicated homogeneous nature of the genotypes within the clusters. The average inter -cluster $\mathrm{D}^{2}$ values (inter -cluster distance) ranged from 3.755 to 11.312. Cluster IV showed maximum inter-cluster (genetic) distance (11.312) from cluster I, suggesting wide diversity between them and the genotypes in these clusters could be used as parents in hybridization programme for generating superior segregants. The result was supported by scatter diagram (Fig. 1) where cluster I and IV were arranged in the farthest position from each other. Moderate/intermediate inter-cluster distance was observed between clusters II and IV (9.9610 followed by clusters III and IV (7.568). Clusters I with III (3.755) and II with III (4.748) had low inter-cluster distance indicating that the genotypes of these clusters were genetically close. The inter-cluster distances were greater than intra-cluster distances, revealing considerable amount of genetic diversity among the genotypes studied (Table 4). 


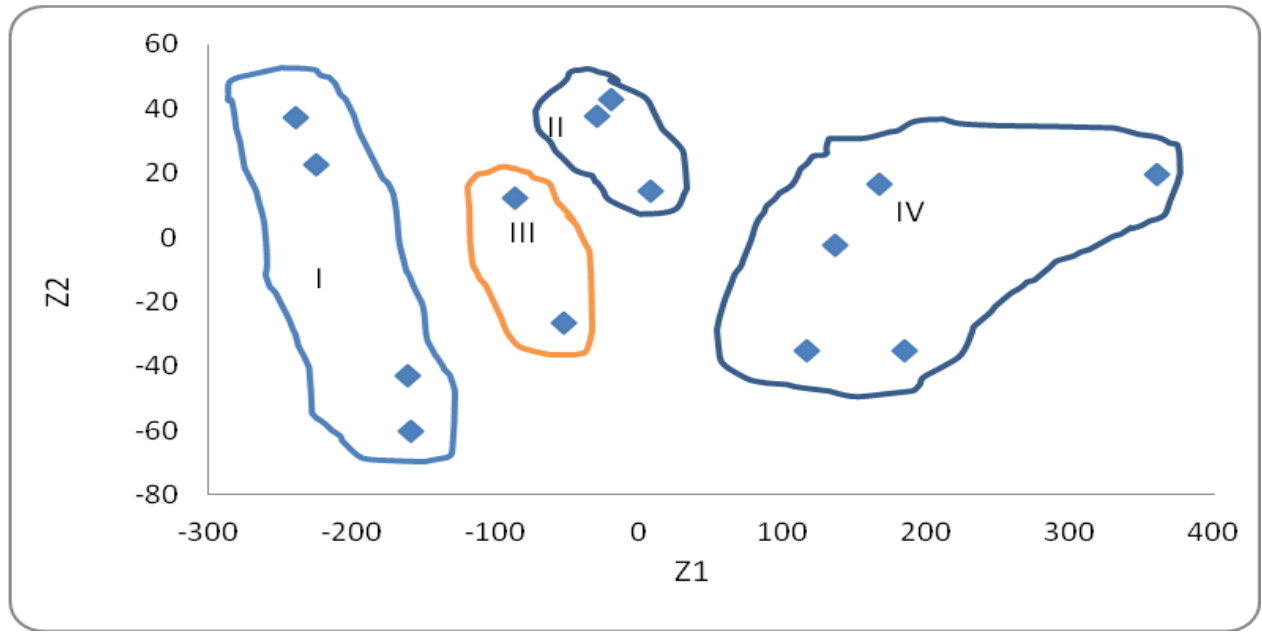

Fig. 1. Scatter distribution of 14 genotypes of papaya based on their principal component scores super imposed with clustering.

Cluster means varied considerably to all characters (Tale 5). Cluster I recorded the highest mean for fruit breadth $(12.97 \mathrm{~cm})$ and skin weight/fruit $(178.79 \mathrm{~g})$, and the second highest mean for plant height at last harvest $(213.33 \mathrm{~cm})$, weight of fruits/plant $(34.20 \mathrm{~kg})$ and fruit yield $(85.48 \mathrm{t} / \mathrm{ha})$ whereas, minimum mean values for cavity length $(12.72 \mathrm{~cm})$, number of seeds/fruit $(216.34)$, weight of seeds/fruit $(91.13 \mathrm{~g})$ and plant height at first harvest $(63.99 \mathrm{~cm})$. Cluster II exhibited maximum mean for cavity breadth $(9.08 \mathrm{~cm})$, TSS $(9.49 \%)$, base girth at $1^{\text {st }}$ harvest $(25.11 \mathrm{~cm})$, base girth at last harvest $(32.67 \mathrm{~cm})$ and desirable minimum values for skin weight/fruit (133.47 g) while the second highest mean values for pulp thickness $(2.76 \mathrm{~cm})$, number of seeds/fruit (397.28), plant height at $1^{\text {st }}$ harvest $(77.95 \mathrm{~cm})$ and number of fruits/plant (28.78). Cluster III recorded the highest mean values for fruit length $(19.46 \mathrm{~cm})$, cavity length $(14.65 \mathrm{~cm})$, plant height at last harvest $(\mathrm{cm})$, number of fruits/plant (32), weight of fruits/plant $(39.85 \mathrm{~kg})$ and fruit yield $(99.59 \mathrm{t} / \mathrm{ha})$. Cluster IV exhibited the maximum mean values for pulp thickness $(2.83 \mathrm{~cm})$, number of seeds/fruit (597.89), weight of seed/fruit (99.54), plant height at $1^{\text {st }}$ harvest $(105.8 \mathrm{~cm})$ and the second highest mean values for fruit length $(17.88 \mathrm{~cm})$, fruit breadth $(12.93$ $\mathrm{cm})$, cavity length $(14.13 \mathrm{~cm})$ and TSS $(9.39 \%)$.

The values of vector-1 and vector-II revealed that both the vectors had positive values for only skin weight/fruit, indicating that this character had the highest contribution towards the divergence among fourteen genotypes (Table 6). In vector-1 the other important characters responsible for genetic divergence in the major areas of differentiation were fruit breadth, cavity length, cavity breadth, TSS\%, weight of seed/fruit, plant height at last harvest, base girth at $1^{\text {st }}$ harvest, number of fruits/plant having positive vector values. In vector-II fruit length, 
pulp thickness, number of seeds/fruit, plant height at first harvest, base girth at last harvest, weight of fruits/plant and fruit yield having positive vector values were important and played a major role in the second axis of differentiation.

Table 5. Cluster mean values for 16 characters of papaya genotypes

\begin{tabular}{l|c|c|c|c}
\hline \multirow{2}{*}{\multicolumn{1}{c}{ Characteristics }} & \multicolumn{4}{c}{ Cluster } \\
\cline { 2 - 5 } Fruit length $(\mathrm{cm})$ & 17.72 & 16.31 & 19.46 & II \\
\hline Fruit bredth (cm) & 12.97 & 12.49 & 12.55 & 12.93 \\
Cavity length (cm) & 12.72 & 13.58 & 14.65 & 14.13 \\
Cavity breadth (cm) & 7.89 & 9.08 & 8.02 & 7.77 \\
TSS\% & 9.28 & 9.49 & 8.74 & 9.39 \\
Pulp thickness (cm) & 2.69 & 2.76 & 2.73 & 2.83 \\
No of seed & 216.34 & 397.28 & 341.95 & 597.89 \\
Weight of seed (g) & 41.13 & 53.89 & 60.34 & 99.54 \\
Skin weight (g) & 178.79 & 133.47 & 171.12 & 164.03 \\
Plant height at 1st harvest (cm) & 63.99 & 77.95 & 76.54 & 105.18 \\
Plant height at last harvest (cm) & 213.33 & 206.66 & 215 & 187.17 \\
Base girth at 1st harvest (cm) & 23.33 & 25.11 & 24.16 & 23.27 \\
Base girth at last harvest (cm) & 29.92 & 32.67 & 30.75 & 29.57 \\
No of fruits & 28.58 & 28.78 & 32 & 27.03 \\
Weight of fruit/plant (kg) & 34.2 & 32.52 & 39.85 & 30.96 \\
yield (t/ha) & 85.48 & 81.29 & 99.59 & 77.32 \\
\hline
\end{tabular}

Table 6. Latent vectors for 16 principal component characters in papaya genotypes

\begin{tabular}{lcc}
\hline Characteristics & Vector - I $\left(\mathrm{Z}_{1}\right)$ & Vector- II $\left(\mathrm{Z}_{2}\right)$ \\
\hline Fruit length $(\mathrm{cm})$ & -0.7899 & 0.9061 \\
Fruit breadth $(\mathrm{cm})$ & 1.274 & -0.8583 \\
Cavity length $(\mathrm{cm})$ & 1.1009 & -0.7961 \\
Cavity breadth $(\mathrm{cm})$ & 2.551 & -2.2492 \\
TSS\% & 0.5087 & -0.193 \\
Pulp thickness $(\mathrm{cm})$ & -5.8065 & 3.8155 \\
No of seed & -0.0164 & 0.0024 \\
Weight of seed $(\mathrm{g})$ & 0.0157 & -0.06 \\
Skin weight & 0.0153 & 0.0123 \\
Plant height at $1 \mathrm{st}$ harvest $(\mathrm{cm})$ & -0.1224 & 0.0305 \\
Plant height at last harvest $(\mathrm{cm})$ & 0.0533 & -0.0231 \\
Base girth at 1 st harvest $(\mathrm{cm})$ & 0.313 & -0.5297 \\
Base girth at last harvest $(\mathrm{cm})$ & -0.5402 & 0.3899 \\
No of fruits/plant & 0.3026 & -0.2304 \\
Weight of fruit/plant $(\mathrm{kg})$ & -0.1206 & 0.0863 \\
yield (ton/ha) & -0.0437 & 0.0307 \\
\hline
\end{tabular}




\section{Conclusion}

It can be concluded that maximum amount of heterosis will be manifested in cross combinations involving the parents belonging to most divergent clusters. In the present study, the maximum inter-cluster distance existed between clusters I and IV and moderate genetic distance between clusters II and IV, and clusters III and IV. It would be possible to generate desirable hybrids by crossing among the genotypes of clusters 1 and IV. But in practical breeding programme, there is a chance to get good hybrid materials when crosses are done among the genotypes of moderate inter-cluster distances. More importantly, desirable hybrids can be obtained when there exists wider genetic distances among parent materials. In this experiment mean values for most of the desirable traits were better in cluster III followed by cluster IV. Therefore, hybridization between the genotypes falling in the clusters III and IV is likely to generate superior genotypes in papaya.

\section{References}

Ahmed, K. 1984. Papaya cultivation. In: Plant, Animal, Bird and Fish wealth. $4^{\text {th }}$ ed. Sarba Janin Granthalaya, 140 New Market, Dhaka. Pp. 300-304.

Anonymous. 2014. Yearbook of Agricultural Statistics-2012 (24 $4^{\text {th }}$ Series). Bangladesh Bureau of Statistics. Ministry of Planning. Govt. of the People's Republic of Bangladesh, Dhaka. p. 117.

Bhatt, G. M. 1973. Multivariate analysis approach to selection of parents for hybridization aiming at yielding improvement of self-pollinated crops. Aust. J. Agric. Res. 21: 1-7.

Bose, T.K. 1990. Papaya. In: Fruits: Tropical and Subtropical. $2^{\text {nd }}$ ed. Naya Prokash, Calcutta-6. India. Pp. 302-328.

Chowdhury, M. A., V. Vandenberg and T. Warkentin. 2002. Cultivar identification and genetic relationship among selected breeding lines and cultivars in chick pea (Cicer arietinum L.). Euphytica. 127 (3): 317-325.

Ghafoor, A., A. Sharif, Z. Ahmad, M. A. Zahid and M. A. Rabbani. 2001. Genetic diversity in blackgram (Vigna mungo L. Hepper). Field Crops Res. 69: 183-190.

Jambhale, V. M., N. S. Kute and S. V. Pawar. 2014. Studies on genetic variability parameters, character association and path analysis among yield and yield contributing traits in papaya (Carica papaya L.). The Bioscan. 9 (4): 1711-1715.

Mahalanobis, P. C. 1936. On the generaliged distance in statistics. Proc. Natl. Inst. Sci. India. 2: 49-55.

Nakasone, H. Y. and R. E. Paull. 1998. Papaya. In: Tropical Fruits. CABI Publishimg, CAB International, Wallingford, Oxon OX 10 8DE, UK. Pp. 239-268.

Ocampo, J. P.,G. E. d'Eeckenbrugge, S. D. Bruyer, L. L. Bellaire and P. Ollitrault. 2006. Organization of morphological and genetic diversity of Caribbean and Venezulean papaya germplasm. Fruit. 61: 25-37. 
Rao, C. R. 1952. Advanced Statistical Methods in Biometric Research. John Willey and Sons, New York. Pp. 351-378.

Saran, P. L., R. Choudhary, I. S. Solanki, P. Patil, S. Kumar. 2015. Genetic variability and relationship studies in new Indian papaya (Carica papaya L.) using morphological and molecular markers. Turk. J. Agric. For. 39: 310-321.

Shukla, S and S. P. Singh. 2002. Genetic divergence in grain amaranthus. Indian J. Genet. Pl. Breed. 62 (4): 336-337.

Singh, R. K. and B. D. Chaudhury. 1985. Biometrical methods in quantitative genetic analysis. Kalayoni Publishers, New Delhi. P. 318.

Singh, S. P. 1991. Genetic divergence and canonical analysis in hyacinth been. J. Genet. and breed. 45(1): 7-12.

Singhania, D.L., D. Singh and R. S. Raje. 2006. Coriader. In: Ravindran, P. R., K. N. Babu, K. N. Shiva. and J. A. Kallupurackal (eds.). Advances in Spices and Achievments of Spices Research in India since Independence. Pp. 678-695. Agrobios (India), Agro House, Behind Nasrani Cinema. Chopasani Road. Jodhpur 342002.

Sudha, R, D. R. Singh, M. Sankaran, S. Singh, V. Damodaran and P. Simachalam. 2013. Genetic diversity analysis of papaya (Carica papaya L.) genotypes in Andaman Islands using morphological and molecular markers. African J. Agril. Res. 8 (41): 5187-5192. 